\title{
DEFENSA JUDICIAL DE LOS DERECHOS HUMANOS EN LOS ESTADOS DE EXCEPCIÓN
}

\author{
Judicial protection of human rights during states of emergency
}

\author{
Lautaro Ríos Álvarez ${ }^{1}$ \\ Universidad de Valparaíso (Chile) \\ estudiorios@entelchile.net
}

RESUM EN: Desde antiguo, en el curso de la historia, los estados han venido atravesando situaciones de crisis entre las que cabe mencionar la guerra externa o interna, las alteraciones graves al orden público, el peligro para la seguridad interior y las calamidades o catástrofes. Tales situaciones habilitan a los Gobiernos para declarar el correspondiente Estado de Excepción Constitucional (E.E.C.) y ejemplo de ellos es la Dictadura romana. En los E.E.C. algunos derechos fundamentales pueden ser limitados con el objeto de subsanar la crisis y volver a la normalidad. La Constitución chilena regula cuatro E.E.C. y garantiza que sólo en el curso de ellos pueden suspenderse o restringirse ciertos derechos fundamentales. Este estudio versa sobre la protección judicial de tales derechos durante los E.E.C.

PALABRAS CLAVE: Situaciones de Crisis, Estados de Emergencia, Estados de Excepción Constitucional, Derechos Fundamentales, Protección Judicial.

ABSTRACT: For ages, throughout the course of history, states have been challenged by critical situations. These have included external or internal wars, significant

1 El autor es Profesor Titular de Teoría Política y Derecho Constitucional de la Facultad de Derecho de la Universidad de Valparaíso. Ex Presidente del Depto. de Derecho Público. Profesor Extraordinario Visitante de la Univ. Santo Tomás de Aquino de Tucumán, Argentina. Magíster en Derecho Público por la Univ. de Chile. Doctor en Derecho por la Univ. Complutense de Madrid. Vicepresidente de la Asociación Chilena de Derecho Constitucional y Miembro Correspondiente de la Asociación Argentina y de la Asociación Peruana de Derecho Constitucional. Consejero Asesor del Anuario Iberoamericano de Justicia Constitucional y Miembro del Consejo Editorial de la Revista "Estudios Constitucionales" de la Universidad de Talca. 
and worrisome breach of public order, dangerous challenges to internal security and catastrophes. Such situations have allowed and authorize governments to declare a Constitutional State of Exception (CSE) and an example of such is the Roman Dictatorship. Whilst a Constitutional State of Exception has been declared, some fundamental and core rights can be limited with the sole objective of ameliorating the crisis and returning to normality.

The Chilean Constitution regulates four CSE and guarantees that only during such situations these core and fundamental rights can be suspended or restricted.

The present paper refers to the judicial protection of such rights during and whilst a CSE.

KEY WORDS: Crisis situation, state of emergency, states of constitutional exception, fundamental rights, judicial protection.

\section{LOS ESTADOS DE EXCEPCIÓN Y LOS DERECHOS HUMANOS²}

\section{Los poderes de crisis}

a lo largo de la Historia:

Es importante, al abordar esta materia, ser conscientes de la notable evolución que ha experimentado, a lo largo de la historia, la relación entre los poderes de crisis y los derechos humanos.

Quien intente emprender un vuelo retrospectivo para indagar los orígenes de los llamados "estados de crisis" o "regímenes de emergencia" o "estados de excepción constitucional", terminará aterrizando en la institución de la Dictadura de la Roma republicana. ${ }^{3}$

Y no porque los llamados "poderes de crisis" hayan tenido lugar sólo en Roma; también hubo dictadores -cuando estuvo amenazada la seguridad o la subsistencia del Estado- en Esparta bajo el nombre de Harmost; en Salónica, donde se les llamó A esymmet; en Malta, donde se les conoció como Archus o en Florencia donde se les denominó Balia,4 sino porque la mejor descripción de los episodios de crisis y de los poderes desplegados para conjurarlos quedó estampada con rasgos indelebles en la fascinante historia de la Roma republicana e imperial.

2 Abreviaturas usadas: AC.: Acta Constitucional; CPR.: Constitución Política de la República (Chile); EEC.: Estados de Excepción Constitucional; LOC.: Ley Orgánica Constitucional; P de la R.: Presidente de la República.

3 Sobre la dictadura romana escribieron, entre otros, Tito Livio, Tácito, Plutarco, Dionisio de Halicarnaso, Suetonio y Cicerón y -entre los clásicos del Renacimiento- Maquiavelo en los "Discorsi sopra la prima deca di Tito Livio"; Bodino en "Los Seis Libros de la República"; y en el S. XX Carl ScHImIT, en su monografía "La Dictadura" (Alianza Editorial, Madrid, 1985).

4 Juan Bodino, ob. cit., L. I, Cap. VIII. 
A hora bien, en aquella época lo único importante para el gobierno era resolver -a cualquier costo- la situación apremiante que exigía el nombramiento de un dictador, sin que éste pudiera ver limitado sus poderes por consideración a los derechos, la fortuna e inclusive la vida de quienes pudieran resultar afectados por sus acciones.

En la visión de M aquiavelo -recogida por Carl Schmitt- el dictador era una autoridad provisional que, sin estar sujeta al concurso ni a la dependencia de ninguna otra, “... adopta disposiciones que puede ejecutar inmediatamente, sin necesidad de otros medios jurídicos (Un uomo que senza alcuna consulta potesse deliberare et senza alcuna appelaggione eseguire le sue deliberazione)". El dictador podía imponer penas con efecto inmediato y de un modo inapelable. Pero, "El dictador no puede modificar las leyes existentes, no puede derogar la Constitución ni la organización de los poderes públicos, ni hacer leyes nuevas... Por ello, la dictadura es una institución constitucional de la República". ${ }^{5}$

El Dictador era designado por el Cónsul, a petición del Senado, por un lapso de seis meses. Sin embargo, era cuestión de honor y una práctica observada religiosamente que, una vez conjurado el peligro o resuelto el asunto que motivara su nombramiento, el dictador resignara de inmediato su poder ante el Senado. ${ }^{6}$

Para Schmitt el dictador romano era un Comisario ejecutivo. Comisario, en cuanto su poder era provisional y estaba definido por el cometido encomendado. Ejecutivo, porque... "en casos de necesidad solamente puede decirse que el dictador puede hacer todo lo que exija la situación de las cosas. Lo que aquí importa no son ya consideraciones jurídicas sino solamente el medio apropiado para lograr un éxito concreto en un caso concreto... Las consideraciones a los derechos contrapuestos, al consentimiento de un tercero que obstaculiza el camino, a los derechos legítimamente adquiridos, al trámite o procedimiento jurídico pueden ser 'imprácticas' y, por lo tanto, perjudiciales y equivocadas en un sentido técnico objetivo". ${ }^{7}$

Así pues, del claro perfil de la dictadura romana -tal como la describen M aquiavelo, Bodino y Schmitt- puede colegirse, en palabras de este último, que el dictador... "no estaba ligado a las leyes y era una especie de rey, con poder ilimitado sobre la vida y la muerte".

Sólo a partir de la primera mitad del siglo XX y, especialmente, luego de concluida la Segunda Guerra M undial y aprobada la Declaración Universal de los Derechos Humanos por la Organización de las Naciones Unidas, la conciencia moral de la humanidad acerca de la dignidad de la persona humana log ró poner cortapisas a los poderes

Carl Schm IтT, ob. cit., p. 37.

6 Es célebre el caso del dictador Lucio Quincio Cincinato (419 A.C.) quien, nombrado para liberar a una legión entrampada por los eucos, los venció en 6 días -según Grimberg- o en 15 -según Bodino- y de inmediato se despojó de su poder ante el Senado.

7 Carl Scнмıाт: ob cit., pp. 41-42. 
exorbitantes otorgados a los gobiernos en los estados de crisis, sometiéndolos a reglas proporcionadas a la gravedad de cada uno de ellos, limitando los derechos fundamentales cuyo ejercicio podía afectarse en tales estados, instaurando acciones procesales destinadas a evitar o a subsanar los abusos de la autoridad y, en fin, estableciendo la responsabilidad de ésta por las irregularidades que pudiera cometer en la aplicación de las medidas adoptadas en dichos estados de excepción.

\section{Los estados de crisis}

a lo ancho de la geografía

Siendo así que los estados de crisis constituyen una patología común a todas las naciones, todos los países del mundo civilizado los contemplan en sus respectivas Constituciones.

A unque se les conoce con distintas denominaciones -estados de emergencia, estados de excepción, estados de crisis, estados de necesidad- ellos siempre obedecen a graves perturbaciones que acaecen en la vida de los pueblos. En la antigua Roma - según Bodino-, la dictadura procedía en los casos de guerra, sedición, sublevaciones o reformas del Estado. ${ }^{8}$

En los estados modernos no se acostumbra designar autoridades especiales con poderes omnímodos en las situaciones de crisis sino que se otorga facultades extraordinarias a los órganos existentes. También cabe señalar que si la situación crítica, a juicio del gobierno, es manejable con sus poderes ordinarios, éste es libre para enfrentar la emergencia sin tener que decretar un estado de excepción. Estos sólo proceden cuando las prerrogativas ordinarias del gobierno no son suficientes para enfrentar la crisis.

En Alemania -a modo de ejemplo- la Constitución regula en su Capítulo Xa el Estado de Defensa (Verteidigungsfall) cuando el territorio federal es atacado por la fuerza de las armas o existe un peligro inminente de que este ataque se produzca. Los artículos $115 \mathrm{a}$ al $115 \mathrm{k}$ regulan los poderes excepcionales en esta situación. ${ }^{9}$

En Francia, su Constitución dispone: "Cuando las instituciones de la República, la independencia de la Nación, la integridad de su territorio o el cumplimiento en sus compromisos internacionales estén amenazados de manera grave o inmediata, y el funcionamiento regular de los poderes públicos constitucionales esté interrumpido, el Presidente de la República tomará las medidas exigidas por tales circunstancias, previa consulta oficial con el Primer Ministro, los Presidentes de las A sambleas y el Consejo Constitucional" (artículo 16).

Juan Bodino, ob. cit., Centro de Estudios Constitucionales, Madrid, 1992, t. I, p. 268.

9 Estos poderes se inspiran en el artículo 148 de la Constitución de Weimar sobre las prerrogativas excepcionales del Presidente del Reich en caso de estado de necesidad (Notstand). 
La Constitución de Portugal prescribe, en su artículo 19: "1. No podrán los órganos de soberanía suspender conjunta ni separadamente el ejercicio de los derechos, libertades y garantías salvo en caso de estado de sitio o de estado de excepción (estado de emergencia) declarado de la forma prevista en la Constitución". Los numerales siguientes de esta disposición contienen un valioso compendio de los principios que deben regir estos estados.

En España, siguiendo la distinción tripartita tradicional en el derecho político español desde la Ley de Orden Público de 1933 (estados de prevención, alarma y guerra), el artículo 116 de la Constitución dispone que: "1. Una ley orgánica regulará los estados de alarma, de excepción y de sitio y las competencias y limitaciones correspondientes". ${ }^{10}$

La Constitución de Rumania, en su artículo 93, prescribe: “(1) El Presidente de Rumania instituye, de acuerdo a la ley, el estado de sitio o el estado de emergencia en todo el país o en ciertos municipios, y solicita al Parlamento la aprobación de la medida adoptada, en un plazo máximo de 5 días desde su adopción.

“(2) Si el Parlamento no está en sesión, se convoca de derecho en un plazo máximo de 48 horas desde la institución del estado de sitio o del estado de emergencia y funciona mientras éstos estén declarados."

La Carta Fundamental de Polonia, en su Título XI, contempla "Las M edidas de Excepción". Su artículo 228 prescribe: "1. En caso de amenaza excepcional, cuando las medidas constitucionales ordinarias son insuficientes, uno de los siguientes estados puede ser proclamado: el estado de sitio, el estado de urgencia o el estado de siniestro."...

"Art. 229. En caso de amenaza exterior del Estado, de agresión armada contra la República de Polonia o cuando los tratados comprometen a la defensa común contra la agresión, el Presidente de la República puede proclamar, a requerimiento del Consejo de Ministros, el estado de sitio sobre una parte o sobre el conjunto del teritorio del país."

"Art. 230. Si el régimen constitucional del Estado, la seguridad de los ciudadanos o el orden público son amenazados, el Presidente de la República puede proclamar por un período determinado, de 90 días o más, y a requerimiento del Consejo de M inistros, el estado de urgencia sobre una parte o sobre el conjunto del territorio del país."...

"Art. 232. Con el fin de prevenir las consecuencias de siniestros o de accidentes tecnológicos que tengan un carácter de siniestro y a objeto de suprimirlas, el Consejo de Ministros puede proclamar por un período determinado de 30 días o más, el estado de siniestro sobre una parte o sobre el conjunto del territorio del Estado. El estado de siniestro puede ser prolongado con el acuerdo de la Dieta."

El art. 233 contempla las restricciones de las libertades y derechos que pueden decretarse durante la vigencia de las medidas de excepción.

10 La Ley Orgánica en referencia es la 4/1981, de 1 de junio. 
Pasemos ahora a examinar sucintamente cómo afrontan las situaciones de crisis algunos estados latinoamericanos.

En la República Argentina la declaración de estos estados es prerrogativa del Poder Ejecutivo. Dice el artículo 99 de la Constitución: "El Presidente de la Nación tiene las siguientes atribuciones: ... 15. Declara la guerra y ordena represalias con autorización y aprobación del Congreso. 16. Declara en estado de sitio uno o varios puntos de la Nación, en caso de ataque exterior y por un término limitado y con acuerdo del Senado. En caso de conmoción interior sólo tiene esta facultad cuando el Congreso está en receso, porque es atribución que corresponde a este cuerpo. El Presidente la ejerce con las limitaciones prescriptas en el artículo 23."

El referido artículo 23 dispone: "En caso de conmoción interior o de ataque exterior que pongan en peligro el ejercicio de esta Constitución y de las autoridades creadas por ella, se declarará en estado de sitio la provincia o territorio en donde exista la perturbación del orden, quedando suspensas allí las garantías constitucionales. Pero durante esta suspensión no podrá el Presidente de la República condenar por sí ni aplicar penas. Su poder se limitará en tal caso respecto de las personas, a arrestarlas o trasladarlas de un punto a otro de la Nación, si ellas no prefiriesen salir fuera del territorio argentino."

También se entiende como estado de emergencia la intervención del Gobierno federal que es garante del goce y el ejercicio de las instituciones de cada provincia (artículo 50 inc. 2) y puede intervenir en el territorio de éstas "para garantir la forma republicana de gobierno o repeler invasiones exteriores, y a requisición de sus autoridades constituidas para sostenerlas o restablecerlas, si hubiesen sido depuestas por la sedición, o por invasión de otra provincia" (artículo 6ㅇ).

La reforma constitucional aprobada en 1994 incorporó la discutida institución de los "decretos de necesidad y urgencia" que el artículo 99 № 3, en su inciso tercero, reguló con rigurosos requisitos que -no obstante su rango constitucional- han sido ominosamente transgredidos en numerosas ocasiones. ${ }^{11}$

Por último, también se menciona entre las instituciones de crisis, la delegación legislativa en caso de emergencia pública, regulada en el artículo 76 de la Carta Fundamental Argentina.

La Constitución del Perú contempla, en su Capítulo VII, el “Régimen de Excepción". Dice el artículo 137: "El Presidente de la República, con acuerdo del Consejo de Ministros, puede declarar, por plazo determinado, en todo el territorio nacional, o en parte de él, y dando cuenta al Congreso o a la Comisión Permanente, los estados de excepción que en este artículo se contemplan:

11 Cfr. Antonio María Hernández: "Las Emergencias y el Orden Constitucional”, UNAM, México, 2003, pp. 29 y sgtes. 
"1. Estado de emergencia, en caso de perturbación de la paz o del orden interno, de catástrofe o de graves circunstancias que afecten la vida de la Nación. En esta eventualidad, puede restringirse o suspenderse el ejercicio de los derechos constitucionales relativos a la libertad y la seguridad personales, la inviolabilidad del domicilio, y la libertad de reunión y de tránsito en el territorio comprendidos en los incisos 9, 11 y 12 del artículo segundo y en el inciso 24, apartado f del mismo artículo. En ninguna circunstancia se puede desterrar a nadie.

"El plazo del estado de emergencia no excede de 60 días. Su prórroga requiere nuevo decreto. En estado de emergencia las Fuerzas Armadas asumen el control del orden interno si así lo dispone el Presidente de la República.

"2. Estado de sitio, en caso de invasión, guerra exterior, guerra civil, o peligro inminente de que se produzcan, con mención de los derechos fundamentales cuyo ejercicio no se restringe o suspende. El plazo correspondiente no excede de 45 días. Al decretarse el estado de sitio, el Congreso se reúne de pleno derecho. La prórroga requiere aprobación del Congreso."

Esta disposición debe concordarse con el artículo 118, en sus numerales 4 y 15 que justifican la intervención del Presidente en estos casos.

En Bolivia el Capítulo IV de la Constitución se refiere a la "Conservación del Orden Público". El artículo 111 prescribe: "En los casos de grave peligro por causa de conmoción interna o guerra internacional, el Jefe del Poder Ejecutivo podrá, con dictamen afirmativo del Consejo de Ministros, declarar el estado de sitio en la extensión del territorio que fuere necesaria.

"Si el Congreso se reuniese ordinaria o extraordinariamente, estando la República o una parte de ella bajo el estado de sitio, la continuación de éste será objeto de una autorización legislativa. En igual forma se procederá si el decreto de estado de sitio fuese dictado por el Poder Ejecutivo estando las Cámaras en funciones.

"Si el estado de sitio no fuere suspendido antes de 90 días, cumplido este término caducará de hecho, salvo el caso de guerra civil o internacional. Los que hubieren sido objeto de apremio serán puestos en libertad, a menos de haber sido sometidos a la jurisdicción de tribunales competentes.

"El Ejecutivo no podrá prolongar el estado de sitio más allá de 90 días, ni declarar otro dentro del mismo año sino con asentimiento del Congreso. Al efecto, lo convocará a sesiones extraordinarias si ocurriese el caso durante el receso de las Cámaras."

El artículo 112 regula los efectos de la declaración de estado de sitio.

La Constitución de Brasil se refiere en su Título V a "LA DEFENSA DEL ESTADO Y DE LAS INSTTTUCIONES DEM OCRÁ TICAS". Su Capítulo I trata del Estado de Defensa y del Estado de Sitio.

El artículo 136 autoriza al Presidente de la República, oídos el Consejo de la República y el Consejo de Defensa Nacional, para decretar el estado de defensa a fin de preservar o restablecer prontamente el orden público o la paz social amenazada por grave e inminente inestabilidad institucional o afectadas por calamidades de la naturaleza de grandes proporciones. 
El artículo 137 autoriza también al Presidente de la República, con iguales requisitos que en el caso anterior, para pedir al Congreso Nacional autorización para decretar el estado de sitio en los casos de I: conmoción grave de repercusión nacional u ocurrencia de hechos que comprueben la ineficacia de las medidas tomadas durante el estado de defensa; II: declaración de estado de guerra o respuesta a la agresión armada extranjera.

Estas disposiciones deben concordarse con el artículo 84, numeral IX que otorga competencia privativa al Presidente de la República para decretar el estado de defensa y el estado de sitio.

La Constitución Política de los Estados Unidos M exicanos, en su artículo 29, prescribe lo siguiente:

“En los casos de invasión, perturbación grave de la paz pública o de cualquier otro que ponga a la sociedad en grave peligro o conflicto, solamente el Presidente de los Estados Unidos Mexicanos, de acuerdo con los titulares de las Secretarías de Estado, los Departamentos Administrativos, y la Procuraduría General de la República y con aprobación del Congreso de la Unión, y, en los recesos de éste, de la Comisión Permanente, podrá suspender en todo el país o en lugar determinado, las garantías que fuesen obstáculos para hacer frente, rápida y fácilmente a la situación; pero deberá hacerlo por un tiempo limitado, por medio de prevenciones generales y sin que la suspensión se contraiga a determinado individuo. Si la suspensión tuviese lugar hallándose el Congreso reunido, éste concederá las autorizaciones que estime necesarias para que el Ejecutivo haga frente a la situación, pero si se verificase en tiempo de receso, se convocará sin demora al Congreso para que las acuerde".

La Constitución Política de Colombia, en su Título VII trata "DE LA RAM A EJECUTIVA", y en el Capítulo 6 de éste, regula "Los estados de excepción".

El artículo 212 prescribe que "El Presidente de la República, con la firma de todos los M inistros, podrá declarar el estado de guerra exterior. Mediante tal declaración el Gobierno tendrá las facultades estrictamente necesarias para repeler la agresión, defender la soberanía, atender los requerimientos de la guerra y procurar el restablecimiento de la normalidad".

El artículo 213 señala que "En caso de grave perturbación del orden público que atente de manera inminente contra la estabilidad institucional, la seguridad del Estado, o la convivencia ciudadana, y que no pueda ser conjurada mediante el uso de las atribuciones ordinarias de las autoridades de policía, el Presidente de la República, con la firma de todos los Ministros, podrá declarar el estado de conmoción interior, en toda la República o parte de ella, por término no mayor de noventa días, prorrogable hasta por dos períodos iguales, el segundo de los cuales requiere consenso previo y favorable del Senado de la República.

"Mediante tal declaración, el Gobierno tendrá las facultades estrictamente necesarias para conjurar las causas de la perturbación e impedir la extensión de sus efectos." 
Dice el inciso 1 del artículo 215: "Cuando sobrevengan hechos distintos a los previstos en los artículos 212 y 213 que perturben o amenacen perturbar en forma grave e inminente el orden económico, social y ecológico del país, o que constituyan grave calamidad pública, podrá el Presidente, con la firma de todos los ministros, declarar el estado de emergencia por perío dos hasta de treinta días en cada caso, que sumados no podrán exceder de noventa días en año calendario."

La Constitución de la República O riental del Uruguay, en su artículo 168, prescribe: "Al Presidente de la República, actuando con el Ministro o Ministros respectivos, o con el Consejo de Ministros, corresponde:

“1ํ) La conservación del orden y tranquilidad en lo interior, y la seguridad en lo exterior.

“17) Tomar medidas prontas de seguridad en los casos graves e imprevistos de ataque exterior o conmoción interior, dando cuenta, dentro de las veinticuatro horas a la Asamblea General, en reunión de ambas Cámaras o, en su caso, a la Comisión Permanente, de lo ejecutado y sus motivos, estándose a lo que estas últimas resuelvan.

"En cuanto a las personas, las medidas prontas de seguridad sólo autorizan a arrestarlas o trasladarlas de un punto a otro del territorio, siempre que no optasen por salir de él. También esta medida, como las otras, deberá someterse, dentro de las veinticuatro horas de adoptada, a la A samblea General en reunión de ambas Cámaras o, en su caso, a la Comisión Permanente, estándose a su resolución.

"El arresto no podrá efectuarse en locales destinados a la reclusión de delincuentes."

Esta es la situación, a grandes rasgos, de los estados de crisis en el mundo europeo y en el ámbito latinoamericano. Como habrá podido advertirse, no obstante la diversa tipología empleada para enunciarlos, las respectivas situaciones obedecen a causas muy similares que van desde la guerra exterior hasta la catástrofe interna, siendo de destacar que los constituyentes han dejado constancia que el propósito principal de los estados de excepción consiste en conjurar la crisis y volver a la normalidad; y que los poderes que tales estados otorgan a la autoridad deben ejercerse sólo en la medida en que sea estrictamente necesario, debiendo ponerse fin a tales estados tan pronto como la emergencia haya sido superada.

\section{Estados de Excepción Constitucional (E.E.C.) en el ordenamiento jurídico chileno y sus caracteres generales}

En Chile, el Acta Constitucional № 4 de 1976 sobre "REGím ENES DE EM ERGENCIA", (DL № 1.553) y la Constitución de 1980 -que recogió su legado- ambas dictadas bajo el Gobierno Militar, vinieron a poner orden en la anarquía existente bajo el imperio de la Constitución de 1925 que las antecedió. En efecto, el artículo 44 de ésta prescribía que "Sólo en virtud de una ley se puede:

“12) Restringir la libertad personal y la de imprenta, o suspender o restringir el ejercicio del derecho de reunión cuando lo reclamare la necesidad imperiosa de la 
defensa del Estado, de la conservación del régimen constitucional o de la paz interior, y sólo por períodos que no podrán exceder de seis meses. Si estas leyes señalaren penas, su aplicación se hará siempre por los tribunales establecidos. Fuera de los casos prescritos en este número, ninguna ley podrá dictarse para suspender o restringir las libertades o derechos que la Constitución asegura."

Pese al mandato riguroso de la oración final que hemos subrayado, con el correr de los años se fue estableciendo, por vía meramente legislativa, una compleja malla de nuevos estados de excepción que reforzaban la autoridad del Gobierno al margen de la Constitución. A modo de ejemplos, cabe señalar la declaración de "zonas de emergencia" en virtud de la ley № 7.200 de 1943; los "Estados de Emergencia" introducidos en el Título VII de la ley № 12.927 sobre Seguridad del Estado, de 1958; y los estados especiales contemplados por la ley № 9.261 de 1948, por la ley № 12.042 de 1956 y por la ley № 16.282 de 1965. O bviamente, en todos estos estados excepcionales se permitía suspender o restringir determinados derechos fundamentales.

El Acta Constitucional (A.C.) № 4 comenzó por establecer una norma de clausura en la afectación del ejercicio de los derechos humanos al prescribir que "Los derechos y garantías que el Acta Constitucional № 3 aseguran a todas las personas, sólo pueden ser afectados en los casos de emergencia que contemplan los artículos siguientes." Esta norma fue recogida por la Constitución de 1980 cuyo artículo 39, en su actual redacción declara: "El ejercicio de los derechos y garantías que la Constitución asegura a todas las personas sólo puede ser afectado bajo las siguientes situaciones de excepción: guerra externa o interna, conmoción interior, emergencia y calamidad pública, cuando afecten gravemente el normal desenvolvimiento de las instituciones del Estado". El texto constitucional garantiza que, bajo ninguna circunstancia, ni aún mediante la dictación de una ley, los derechos fundamentales pueden ser restringidos, salvo en los cuatro casos de crisis que la disposición contempla y sólo por el lapso en el cual dichos estados se encuentren rigiendo.

Tanto el A.C. № 4 como la Constitución vigente supieron distinguir los "casos de emergencia" o "situaciones de excepción" de los "estados de excepción" respectivos. Los casos o situaciones de excepción son circunstancias de hecho que afectan gravemente la vida del Estado, pero que pueden -eventualmente- subsanarse con los mecanismos ordinarios que la ley provee. En otras palabras, una situación de emergencia no desencadena necesariamente el estado de excepción correspondiente sino que solamente habilita a la autoridad para declararlo. El estado de excepción, en cambio, comporta la implantación de un estatuto jurídico que dota a la autoridad de prerrogativas extraordinarias destinadas a resolver la crisis.

La Carta de 1980 contempla cuatro estados de excepción: el estado de asamblea que puede declararse en caso de guerra exterior; el estado de sitio, en caso de guerra interna o de grave conmoción interior; el estado de catástrofe, en caso de calamidad pública; y el estado de emergencia, en caso de grave alteración del orden público o de grave daño para la seguridad de la Nación. 
Los estados de excepción se declaran mediante la dictación de un Decreto Supremo que debe ser firmado por el Presidente de la República y los M inistros del Interior y de Defensa Nacional. Todos ellos comienzan a regir desde la fecha de su publicación en el Diario Oficial (artículo 8은. № 18.415 sobre E.E.C.).

Tanto el estado de asamblea como el estado de sitio requieren, además, el acuerdo del Congreso Nacional. Este dispone de un plazo de cinco días a contar de la fecha en que el Presidente someta a su consideración la declaración de estos estados, debiendo pronunciarse aceptando o rechazando la proposición sin que pueda introducirle modificaciones. Si el Congreso no se pronuncia dentro del plazo señalado, se entiende que aprueba la proposición presidencial. No obstante, el Presidente puede aplicar de inmediato el estado de asamblea o de sitio, mientras se pronuncia el Congreso. Sin embargo, las medidas que adopte el Presidente en tanto no se reúna el Congreso Nacional, podrán ser objeto de revisión por los tribunales de justicia, en todo caso. Tratándose del estado de sitio, el Presidente, mientras se pronuncia el Congreso, sólo podrá restringir el ejercicio del derecho de reunión.

En cuanto al lapso por el cual estos estados pueden declararse, éste resulta indeterminable con respecto al estado de asamblea por la misma razón que es imposible establecer cuándo terminará una guerra exterior. Sin embargo, el Presidente puede disponer la suspensión de este estado antes de que la situación de guerra concluya (artículo 40, inc. final C.P.R.).

El estado de sitio sólo podrá declararse por un plazo de 15 días, pudiendo el Presidente -no obstante- solicitar su prórroga al Congreso.

El estado de catástrofe, en caso de calamidad pública, no tiene plazo prescriptivo. Sin embargo, el Congreso Nacional puede dejar sin efecto su declaración transcurridos 180 días desde la fecha de ésta, si las razones que lo motivaron hubieren cesado en forma absoluta. Con todo, el Presidente sólo puede declarar el estado de catástrofe por un lapso superior a un año, con acuerdo del Congreso Nacional.

El estado de emergencia, en caso de grave alteración del orden público o de grave daño para la seguridad de la Nación, no puede extenderse por más de quince días, pudiendo el P. de la R. prorrogarlo por igual período. Sin embargo, para prórrogas posteriores, el Presidente requerirá siempre del acuerdo del Congreso Nacional.

Caracteres generales de los estados de excepción constitucional.

Los estados de excepción constitucional en Chile se encuentran sometidos al imperio de dos normas matrices. La primera - contenida entre las "BASES DE LA INSTITUCIONA LIDAD"- prescribe que "El ejercicio de la soberanía reconoce como limitación el respeto a los derechos esenciales que emanan de la naturaleza humana" (cap. I, art. $5^{\circ}$ inc. $2^{\circ}$ ). Y la segunda -la del art. 39, al que ya hicimos referencia- constituye una limitación específica de estos estados de crisis, según la cual el ejercicio de los 
derechos y garantías que la Constitución asegura a todas las personas sólo puede ser afectado bajo la vigencia de las cuatro situaciones de excepción constitucional que la misma disposición contempla.

No obstante el plazo por el cual algunos de ellos pueden ser declarados, el Presidente de la República, en cualquier momento puede ponerles término y debe hacerlo cuando cesa la situación que dio motivo a su declaración. En el tema que nos interesa, el art. 44, inc. 20, prescribe: "Las medidas que se adopten durante los estados de excepción no podrán, bajo ninguna circunstancia, prolongarse más allá de la vigencia de los mismos".

Durante un E.E.C. sólo puede suspenderse o restringirse el ejercicio de aquellos derechos específicamente autorizados por la Constitución. Se entiende suspender un derecho "cuando temporalmente se impide del todo su ejercicio durante la vigencia de un E.E.C.". Se entiende restringir un derecho "cuando, durante la vigencia de un E.E.C., se limita su ejercicio en el fondo o en la forma" (art. 12, LOC. № 18.415).

Pueden coexistir simultáneamente dos o más E.E.C. siempre que -al momento de su declaración- existan las respectivas situaciones de crisis que habilitan a la autoridad para decretarlos.

Finalmente, las potestades que se otorgan a las autoridades en los E.E.C. deben estar dirigidas a subsanar las causas que les dieron origen y al pronto restablecimiento de la normalidad constitucional. En ningún caso aquéllas pueden afectar las competencias ni el funcionamiento de los órganos constitucionales ni los derechos e inmunidades de sus respectivos titulares (art. 44, C.P.R.). ${ }^{12}$

\section{Derechos fundamentales susceptibles de ser afectados en los E.E.C. y su grado de afectación}

Ya advertimos que sólo el ejercicio de determinados derechos pueden ser afectados en los E.E.C. y los verbos rectores de esta afectación consisten en suspenderlos o restringirlos, hallándose legalmente definidos estos conceptos, como también vimos.

4.1. Declarado el estado de asamblea, ${ }^{13}$ el Presidente de la República puede suspender o restringir el ejercicio de la libertad personal o ambulatoria, del derecho de reunión y de la libertad de trabajo.

12 El resultado abusivo y hasta escarnecedor que sufren a veces los opositores al gobierno de turno es casi inevitable. Bajo el texto original de la Carta de 1833 -esto es, antes de la reforma de octubre de 1874se detuvo y confinó a congresales a lugares apartados del territorio, sin respetar sus prerrogativas parlamentarias. Durante uno de los E.E.C. dictados por el Gobierno Militar, se expulsó del país a un político emblemático por su pacifismo como era don Bernardo Leighton.

13 La instauración de este estado no requiere la declaración formal de guerra -que sólo puede hacerse por el Presidente de la República previa autorización por ley (arts. 32 - № 19 y 63 №15)- sino que basta la situación de hecho de guerra exterior (art. 8 OC. № 18.415). 
Puede, también, restringir el ejercicio del derecho de asociación, interceptar, abrir o registrar documentos y toda clase de comunicaciones; disponer requisiciones de bienes y establecer limitaciones al ejercicio del derecho de propiedad (art. 43 inc. 1ㅇ, C.P.R.).

4.2. Durante el estado de sitio, el Presidente de la República puede restringir la libertad de locomoción y arrestar a las personas en sus propias moradas o en los lugares que la ley determine y que no sean cárceles ni estén destinados a la detención o prisión de reos comunes.

Puede, también, suspender o restringir el ejercicio del derecho de reunión (art. 43, inc. $2^{\circ}$, C.P.R.).

4.3. En el estado de catástrofe, el Presidente de la República puede restringir el ejercicio de las libertades de locomoción y de reunión.

Puede, también, disponer requisiciones de bienes, establecer limitaciones al ejercicio del derecho de propiedad y adoptar todas las medidas extraordinarias de carácter administrativo que sean necesarias para el pronto restablecimiento de la normalidad en la zona afectada (art. 43, inc. 30, C.P.R.).

4.4. Declarado el estado de emergencia el Presidente de la República puede restringir el ejercicio de las libertades de locomoción y de reunión (art. 43, inc. 4으, C.P.R.).

Resulta oportuno señalar que la notable modificación general introducida por la Ley de Reforma № 20.050 -el año 2005- a la Constitución, culminó una serie de modernizaciones al texto de 1980, aprobado durante el gobierno militar, entre las que tienen especial relieve las concernientes a los E.E.C. en cuanto a los órganos que intervienen en su declaratoria, a los plazos de vigencia de aquéllos susceptibles de regulación temporal, en lo tocante a la reducción del listado de derechos que pueden ser afectados en ellos y, particularmente, en lo que respecta al fortalecimiento de la defensa judicial de las personas agraviadas.

En la Constitución original tenía una intervención relevante el Consejo de Seguridad Nacional (COSENA), órgano expresivo del poder militar, compuesto por una mayoría de uniformados sobre las autoridades civiles, encargado -entre otras materiasde asesorar al Presidente de la República en cualquier asunto vinculado a la seguridad nacional. Era indispensable el acuerdo del COSENA para que el Presidente de la República pudiera declarar el estado de asamblea. Y, con su acuerdo previo, el Presidente podía aplicar el estado de sitio de inmediato, mientras estaba pendiente el pronunciamiento del Congreso acerca de su declaración. En fin, el acuerdo del COSENA era requisito prescriptivo para que el Presidente pudiera declarar el estado de emergencia y hasta el estado de catástrofe. La reforma de 2005 puso término definitivo a esta intervención exorbitante y entregó la declaración de los E.E.C. a órganos de la democracia representativa, de elección popular, como son el P. de la R. y el Congreso.

En lo que respecta a la reducción del listado de derechos susceptibles de ser afectados durante los estados de crisis, también se advierte una notoria diferencia entre la Constitución original de 1980 y la Carta Fundamental actualmente vigente. 
En el estado de asamblea la autoridad no puede, ahora, suspender o restringir la libertad de información y la de expresión, como ocurría originalmente. Tampoco, en este estado excepcional, puede restringir el derecho de sindicación.

En el estado de sitio el Presidente no puede, en la actualidad, trasladar a las personas de un punto a otro del territorio nacional, lo que daba origen a la ominosa institución de la relegación en virtud de la cual una persona podía ser confinada a cualquiera localidad urbana del país, quedando desprovista no sólo de su sustento sino también de su entorno familiar y de toda conexión con su medio social; en cambio, puede restringir la libertad de locomoción. Tampoco el Presidente puede prohibir a determinadas personas la entrada y salida del país ni expulsarlas del territorio nacional, como ocurrió con frecuencia durante el régimen militar dando origen al exilio masivo de los opositores al gobierno a los más diversos países de América y de Europa. La más agravante circunstancia de estas medidas es que ellas mantenían su vigencia, "pese a la cesación del estado de excepción que les dio origen en tanto la autoridad que las decretó no las deje expresamente sin efecto". Tampoco puede, ahora, en el estado de sitio, suspender ni restringir la libertad de información y de expresión ni restringir el ejercicio de los derechos de asociación y de sindicación ni imponer censura a la correspondencia y a las comunicaciones; to do lo cual estaba prescrito en el texto original de la Constitución de 1980.

En el estado de catástrofe el P. de la R. no puede, actualmente, restringir la libertad de reunión como ocurría originalmente.

En el estado de emergencia no puede el P. de la R., en la actualidad, prohibir a determinadas personas la entrada y salida del territorio; tampoco puede suspender el derecho de reunión ni suspender o restringir la libertad de información y de opinión. Sólo puede restringir las libertades de locomoción y de reunión.

Finalmente, en lo que respecta a la defensa judicial de las personas agraviadas, la Reforma de 2005 culminó un proceso de giro copernicano a la situación regulada en la Constitución original de 1980. En efecto, el recurso de habeas corpus no era procedente en los estados de asamblea y de sitio, respecto de las medidas adoptadas por la autoridad competente con sujeción a las normas establecidas por la Constitución y la ley. El recurso de protección tampoco procedía, en ninguno de los estados de excepción, respecto de los actos o medidas adoptados por la autoridad con sujeción a la Constitución y a la ley, que afectaran a los derechos constitucionales cuyo ejercicio podía suspenderse o restringirse en conformidad a las normas que regían dichos estados. En resumen, bajo la Carta original de 1980, los derechos fundamentales de las personas quedaban a la intemperie en los estados de crisis. 


\section{DEFENSA JUDICIAL DE LOS DERECHOS HUMANOS EN LOS ESTADOS DE EXCEPCIÓN CONSTITUCIONAL}

El único poder independiente e idóneo para resguardar los derechos de las personas injusta o arbitrariamente afectadas en los E.E.C., es el Poder Judicial. De tal manera, la defensa judicial de los derechos humanos sólo puede hacerse efectiva mediante el ejercicio de las acciones y recursos que la Constitución otorga a aquéllos cuyos derechos fundamentales se vean indebidamente atropellados por efecto de las medidas adoptadas por el gobierno en estos estados.

\section{Protección judicial del numerus clausus} de los E.E.C. y sus circunstancias habilitantes

No basta con establecer en la Constitución los cuatro estados excepcionales que hemos relatado y prescribir que sólo en virtud de ellos puede afectarse el ejercicio de los derechos y garantías que la Constitución asegura. Los gobiernos despliegan a veces una ingeniosa batería de arbitrios para disfrazar la situación real que no les acomoda, a fin de enmarcarla dentro del estado excepcional que les interesa declarar.

Por otra parte, las Constituciones son guardianas muy celosas del principio de división de las funciones al momento de blindar la autonomía del gobierno para decretar estos estados. No sabemos de ninguna Constitución que permita al Poder Judicial interferir o controlar esta atribución exclusiva del Gobierno.

Para equilibrar estos dos extremos, la Reforma de 2005 ideó la siguiente disposición:

“Artículo 45. Los Tribunales de Justicia no podrán calificar los fundamentos ni las circunstancias de hecho invocados por la autoridad para decretar los estados de excepción, sin perjuicio de lo dispuesto en el artículo 39."

Esta última frase quiere decir que, no obstante la prohibición impuesta a los jueces de calificar los motivos invocados por la autoridad para decretar los E.E.C., ellos pueden intervenir en los siguiente casos: A) cuando la autoridad decretare un E.E.C. no contemplado en el artículo 39 de la Carta; B) si el fundamento o la circunstancia de hecho en que se funda un estado de excepción no corresponde al que ha sido decretado; y C) cuando la autoridad decreta un estado de excepción con ausencia de todo fundamento de hecho o motivo habilitante para hacerlo de acuerdo a la Constitución.

Como, además, la Reforma de 2005 agregó al artículo 39, como requisito para decretarlos, que las situaciones de excepción "afecten gravemente el normal desenvolvimiento de las instituciones del Estado", pensamos que también podría impugnarse la declaración de un estado de excepción cuando la circunstancia que le dio origen no cumple este requisito necesario para su procedencia. 
En estos casos los tribunales no entran a calificar si la autoridad tuvo o no motivo suficiente para declarar el estado de excepción que se impugna; sino que controlan la congruencia entre el E.E.C. que se dicta y la situación de crisis que lo autoriza conforme a la Constitución, estando habilitados para ejercer este control en virtud de la frase final de la disposición transcrita.

\section{Amplitud de los medios de defensa de los derechos humanos}

El artículo 45 citado continúa así: "No obstante, respecto de las medidas particulares que afecten derechos constitucionales, siempre existirá la garantía de recurrir ante las autoridades judiciales a través de los recursos que corresponda".

Este precepto significa un cambio cualitativo de importancia con relación a la situación original descrita anteriormente, la que hacía improcedente la acción de habeas corpus en los estados de asamblea y de sitio respecto de las medidas adoptadas en virtud de ellos con sujeción a las normas establecidas por la Constitución y la ley. Para rechazar miles de recursos de amparo interpuestos en estos estados, durante el Gobierno Militar, por medidas atentatorias de la libertad personal, generalmente desprovistas de todo motivo, los tribunales llegaron a utilizar una fórmula sacramental: “Habiéndose dictado la medida que se impugna en virtud de un estado de excepción que la contempla, por la autoridad competente y en conformidad a las normas constitucionales y legales aplicables al caso, se declara improcedente el recurso de amparo interpuesto".

La actual normativa supera también el modesto avance de la Ley de Reforma № 18.825 de 1989 la que -en lo pertinente- señalaba: “La interposición y tramitación de los recursos de amparo y de protección que conozcan los tribunales no suspenderán los efectos de las medidas decretadas, sin perjuicio de lo que resuelvan en definitiva respecto de tales recursos".

El texto de la Constitución reformada el año 2005 no hace referencia particular a ningún recurso o acción sino que garantiza siempre el derecho de recurrir a los tribunales competentes en defensa de cualquier derecho constitucional agraviado por las medidas que se adopten en estos estados. Por consiguiente, no sólo proceden las acciones de rango constitucional -incluidos el habeas corpus y la acción de protección- sino también todas aquellas que, teniendo solamente jerarquía legal, están destinadas a resguardar el ejercicio de tales derechos.

La disposición transcrita viene a reiterar -aun en los estados de excepción- el principio de tutela jurisdiccional establecido en el artículo 19 № 3 cuando éste asegura a todas las personas "la igual protección de la ley en el ejercicio de sus derechos". Y continúa diciendo: "Toda persona tiene derecho a defensa jurídica en la forma que la ley señale...". 
Las ventajas comparativas del nuevo artículo 45 son las siguientes: A) las medidas que afecten derechos constitucionales serán siempre susceptibles de impugnación judicial; B) ésta podrá ser objeto tanto de las acciones constitucionales de amparo y de protección como de las demás acciones ordinarias que procedan, según el caso; y C) con respecto a estas medidas no sólo podrán los tribunales calificar sus fundamentos y circunstancias de hecho sino también su existencia y su proporcionalidad; lo que antes era ilusorio ante el tenor categórico de la disposición que decía que "Los tribunales de justicia no podrán, en caso alguno, entrar a calificar los fundamentos ni las circunstancias de hecho invocados por la autoridad para adoptar las medidas en el ejercicio de las facultades excepcionales que le confiere esta Constitución" (artículo 41 , No 3 C.P.R. original).

\section{Una sombra perturbadora: ausencia del principio de responsabilidad por daños personales}

Hace ya más de un siglo atrás, nuestro destacado iuspublicista don Valentín Letelier sostenía que "en las Repúblicas no debe haber funcionarios irresponsables". ${ }^{14}$ Podría añadirse que, a mayor poder ejercido, corresponde mayor responsabilidad.

Los E.E.C. generan poderes excepcionales - los llamados "poderes de crisis"- cuyo ejercicio puede desbordar los límites autorizad os y puede inferir agravios injustificados a las personas afectadas.

En un Estado de Derecho republicano y democrático como el nuestro, debiera existir una norma constitucional que no sólo estableciera la responsabilidad patrimonial del Estado en los casos de perjuicios de esta naturaleza sino también la responsabilidad personal de los agentes del Estado que, infringiendo la Constitución o la ley, ocasionaren daños a las personas en el ejercicio de los poderes de crisis.

El art. 55을 la Constitución española, que trata "De la suspensión de los derechos y libertades", prescribe en su inciso final: "La utilización injustificada o abusiva de las facultades reconocidas en dicha ley orgánica producirá responsabilidad penal, como violación de los derechos y libertades reconocidos por las leyes". ${ }^{15}$

El art. 214으으 5 de la Constitución de Colombia -situado en el capítulo que trata "De los estados de excepción"- prescribe: "El Presidente y los Ministros serán responsables cuando declaren los estados de excepción sin haber ocurrido los casos de guerra exterior o de conmoción interior, y lo serán también, al igual que los demás funcionarios, por cualquier abuso que hubieren cometido en el ejercicio de las facultades a que se refieren los artículos anteriores".

14 Cit. por el Prof. Enrique Silva Cimma: “Estado, Gobierno, Ciencia Política y Derecho Público”, Ed. Universitaria, Santiago, 2008, p. 23.

15 La Ley Orgánica citada es la № 4/1988 de 25 de mayo, sobre Enjuiciamiento Criminal. 
Similar causal de responsabilidad del Presidente de la República y de los Ministros de Estado establece el artículo 215, inciso 8o, con respecto a la declaración infundada del estado de emergencia y a los abusos que se cometieren en el ejercicio de las facultades que la Constitución otorga al Gobierno en dicho estado.

El artículo $112^{\circ}$ de la Constitución de Bolivia, que se refiere a los efectos del estado de sitio, contiene -en su apartado № 5- la disposición siguiente: "Los ejecutores de órdenes que violen estas garantías podrán ser enjuiciados en cualquier tiempo, pasado que sea el estado de sitio, como reos de atentado contra las garantías constitucionales, sin que les favorezca la excusa de haber cumplido órdenes superiores".

El artículo 141으 de la Constitución de Brasil establece: "Cesado el estado de defensa o el estado de sitio, cesarán también sus efectos, sin perjuicio de la responsabilidad por los ilícitos cometidos por sus ejecutores o agentes".

En el derecho constitucional chileno sólo se contempla la responsabilidad patrimonial del Estado, conforme al artículo $45^{\circ}$ inciso 2 - que establece: "Las requisiciones que se practiquen (durante los E.E.C.) darán lugar a indemnizaciones en conformidad a la ley. También darán derecho a indemnización las limitaciones que se impongan al derecho de propiedad cuando importen privación de alguno de sus atributos o facultades esenciales y con ello se cause daño".

La LOC № 18.415 sobre los Estados de Excepción, que regula esta materia, establece que, en los casos señalados precedentemente, habrá lugar a la indemnización de perjuicios en contra del Fisco, siempre que los mismos sean directos. Añade que "la interposición de dicha acción no suspenderá, en caso alguno, la respectiva medida" (art. 170). En el caso de las limitaciones que se impongan al derecho de propiedad, bastará que la autoridad notifique al afectado dejándole copia del documento que dispuso la respectiva limitación (art. 18ㅇinc. $2^{\circ}$ ).

A ñade el art. 19 que "El monto de la indemnización y su forma de pago serán determinados de común acuerdo entre la autoridad que ordenó la requisición y el afectado por la medida". En caso de no lograrse acuerdo, el afectado puede recurrir dentro del plazo de 30 días ante el Juez Civil competente. El Tribunal dará a esta presentación una tramitación incidental -esto es, breve y sumaria- fijando en su sentencia el monto definitivo de la indemnización, la que debe ser pagada en dinero efectivo y al contado (art. 19ㅇ). La acción indemnizatoria prescribe en el plazo de un año a contar de la fecha de término del estado de excepción que dio origen a la medida que ocasionó el perjuicio.

Exceptuando las normas sancionatorias existentes en el derecho penal y en el derecho administrativo, echamos de menos en nuestro derecho público una normativa que establezca la responsabilidad de las autoridades y funcionarios por los abusos y extralimitaciones que puedan cometer en el ejercicio de las facultades extraordinarias que se les otorgan en los estados de excepción constitucional. 
$-000-$

El notable maestro, Profesor Luís Sánchez A gesta, en el Prólogo de la tesis doctoral del Prof. Francisco Fernández Segado, acerca de los Estados de Excepción Constitucional en España, expresó lo siguiente: "Los poderes de excepción suponen una situación anormal, y lo anormal es en cierta forma imprevisible". Y concluyó así: "En todo caso debemos también considerar como un fruto agridulce de la civilización, el que las Constituciones prevean procedimientos lícitos de excepción que, en cierta manera, estén sujetos a un control de su legalidad. Este esfuerzo es quizá el mejor fruto de la ciencia jurídica constitucional por normalizar lo anormal y prevenir lo imprevisible".

$-000-$

\section{BIBLIOGRAFÍA}

Bodino, Juan: (1992) "Los Seis Libros de la República", Madrid, Centro de Estudios Constitucionales.

Bulnes Aldunate, Luz: (2005) "Reforma Constitucional" ("Los Estados de Excepción frente a la Reforma Constitucional"), Coord. Francisco Zúñiga Urbina, Santiago, LexisNexis.

Caffarena de Jiles, Elena: (1957) "El Recurso de Amparo frente a los Regímenes de Emergencia", Santiago de Chile, Imp. San Francisco.

Cruz Villalón, Pedro: (1984) "Estados Excepcionales y Suspensión de Garantías", Madrid, Ed. Tecnos.

Escobar Fornos, Iván: (2003) “Los Derechos Humanos y su Defensa”, Managua, Nicaragua, Imp. La Prensa S.A.

Fernández Segado, Francisco: (1977) “El Estado de Excepción en el Derecho Constitucional Español", Madrid, Edit. de Derecho Reunidas.

Fix-ZAmudio, Héctor: (1982) "La Protección Procesal de los Derechos Humanos ante las Jurisdicciones Nacionales", Madrid, Ed. Civitas.

García Pino, Gonzalo: (2005) "Reforma Constitucional" ("Los Estados de Excepción Constitucional: Un nuevo Derecho de Excepción"), Santiago, LexisNexis.

HernÁndez, Antonio María: (2003) "Las Emergencias y el Orden Constitucional", 2a Ed., México D.F., UNAM.

Maquiavelo, Nicolás: "Discorsi Sopra la Prima Deca di Tito Livio".

Pfeffer Urquiaga, Emilio: (2005) "Reformas Constitucionales 2005" ("Estados de Excepción Constitucional"), Santiago, Ed. Jurídica de Chile.

Ríos Álvarez, Lautaro: (2005) "La Constitución Reformada de 2005" ("Los Estados de Excepción Constitucional en una Perspectiva Humanista") Coord. Humberto Nogueira Alcalá, Santiago, LexisNexis.

Ríos Álvarez, Lautaro: (2006) "Los Estados de Crisis en el nuevo Ordenamiento Constitucional Chileno", XXXV Jornadas Chilenas de Derecho Público, T. I, Universidad de Valparaíso, Valparaíso, Edeval. 
Saenger Gianoni, Fernando y Jiménez Loosli, Fernando: (2005) "Reforma Constitucional" ( "Los Estados de Excepción Constitucional"), Santiago, LexisNexis.

Schm ITt, Carl: (1985) "La Dictadura”, Madrid, Alianza Editorial.

Vega Méndez, Francisco: (2005) "Reforma Constitucional" ("Notas para una Teoría de la Excepción. En Torno a la Reforma Constitucional de 2005 en Chile"), Santiago, LexisNexis.

ZúÑIGA URBINA, Francisco: (2005) "Derecho de Excepción en la Reforma Constitucional en Chile", Ponencia a la M esa Redonda -A sociación A rgentina de Derecho Constitucional, Córdoba, Argentina. 